Schweiz. Z. Tuberk. 1961;18:217

\title{
Klinische Demonstrationen
}

H.

Steinlin

St. Gallen

Adresse des Autors: Dr. H.Steinlin, oberer Graben, 11 St. Gallen.

Es werden zuerst 2 Fälle von schwerer doppelseitig-kavernöser Lungentuberkulose, im einen Fall kombiniert mit tuberkulöser Peritonitis bei italienischen Fremdarbeitern, einem

Geschwisterpaar, demonstriert. Die Erkrankung trat bei beiden 9 Monate nach Grenz-übertritt mit negativem Röntgenbefund auf. Zum Problem der Differenzialdiagnose kavernöser Lungenveränderungen werden 2 Fälle von Kavernenbildungen demonstriert, die nach ihrem Verlauf als Lungenabszesse interpretiert werden mußten, dann ein Fall von Zwerchfellhernie mit Darmschlingen im Pleuraraum, die zuerst als Echinokokkuszysten aufgefaßt wurden und ein Fall von Megaoeso-phagus, der als Lungenspitzenkaverne imponierte. 